\title{
Occupational Differences by Race and Ethnicity in the United States, 2007-2018
}

\author{
Kusum Singh ${ }^{1 *}$ \\ ${ }^{1}$ Division of Business and Economic Development, LeMoyne-Owen College, 807 Walker \\ Avenue, Memphis, TN 38126, USA \\ *Corresponding author: Division of Business and Economic Development, LeMoyne-Owen \\ College, 807 Walker Avenue, Memphis, TN 38126, USA. E-mail: kusum_singh@loc.edu
}

Received: April 23, 2020 Accepted: June 4, 2021 Published: June 24, 2021

doi: 10.5296/rae.v13i2.18559 URL: https://doi.org/10.5296/rae.v13i2.18559

\begin{abstract}
This study examines the extent and reasons for differences in occupational distributions by race and ethnicity in the U.S. labor market from 2007 to 2018. Using IPUMS data, the study found that racial differences in occupational distributions were lower than ethnic disparities in occupational distributions. Racial disparity in occupational distributions increased slightly, while the ethnic disparity in occupational distributions decreased from 2007 to 2018 . In addition, racial and ethnic disparities in occupational distributions were found to be not only due to observed socio-demographic variables of workers but also due to other unexplained factors. The effect of unexplained variables had more pronounced effects on the racial differences in occupational distributions than on the ethnic differences in occupational distributions.
\end{abstract}

Keywords: occupational differences, occupational segregation, race, ethnicity, minorities, African Americans, Hispanics

JEL classification: J1 1, J15, J62 


\section{Introduction}

During the Great Recession years from 2007 to 2009, the national unemployment rates of the U.S. increased from 4.62 percent to 9.28 percent (See Table 1). Whites, African Americans, and Hispanics all experienced an increase in unemployment rates during the Great Recession years. However, African Americans relative to Whites and Hispanics had the highest unemployment rates ranging from 8.26 percent in 2007 to 14.78 percent in 2009. After 2010, the U.S. economy exhibited signs of economic progress in several economic indicators such as unemployment rates. The national unemployment rates dropped to 3.89 percent by 2018 . African Americans' and Hispanics' unemployment rates also fell to 6.49 percent and 4.68 percent, respectively, by 2018. As the unemployment rates in the U.S. economy had significantly decreased by 2018, it would be interesting to know if there were any changes in the occupational distributions by race and ethnicity in the U.S. labor market over this period. Since African Americans and Hispanics are the largest minority groups(Note 1) in the U.S. population, in this study, I compare the occupational distributions of African Americans and Hispanics with Whites, the largest racial majority group in the U.S. population, from 2007 to 2018 .

Table 1. Unemployment Rates in the U.S. Economy

\begin{tabular}{lllll}
\hline & \multicolumn{4}{l}{ Unemployment Rates (\%) } \\
\cline { 2 - 5 } Year & Nation & Whites & African Americans & Hispanics \\
\hline 2007 & 4.62 & 4.12 & 8.26 & 5.64 \\
2008 & 5.80 & 5.19 & 10.10 & 7.62 \\
2009 & 9.28 & 8.49 & 14.78 & 12.08 \\
2010 & 9.61 & 8.72 & 15.96 & 12.49 \\
2011 & 8.93 & 7.93 & 15.83 & 11.49 \\
2012 & 8.08 & 7.19 & 13.83 & 10.32 \\
2013 & 7.36 & 6.51 & 13.07 & 9.11 \\
2014 & 6.16 & 5.30 & 11.34 & 7.40 \\
2015 & 5.28 & 4.58 & 9.56 & 6.60 \\
2016 & 4.88 & 4.28 & 8.43 & 5.78 \\
2017 & 4.34 & 3.81 & 7.48 & 5.13 \\
2018 & 3.89 & 3.46 & 6.49 & 4.68 \\
\hline
\end{tabular}

Source: U.S. Bureau of Labor Statistics. Retrieved on October 30, 2020 from https://data.bls.gov/timeseries/LNS14000006

Previous studies have documented the presence of disparities in occupational distributions by race or/and ethnicity in the U.S. labor market (e.g., Gabriel et al. 1990, Queneau 2006, Tomaskovic-Devey et al. 2006, Hellerstein and Neumark 2008, Queneau 2009, Alonso-Villar et al. 2012). Similarly, other studies have examined determinants for occupational differences by race or/and ethnicity in the U.S. labor market (e.g., Semyonov et al. 2000, Gabriel et al. 
1990, Hamilton et al. 2011, Alonso-Villar et al. 2013, Gradin et al. 2015). Although previous studies provide valuable information related to the extent and factors for occupational differences by race and ethnicity in the U.S. workforce, this study adds to the previous studies on racial and ethnic differences in occupational distributions in two ways. First, most studies dealing with differences in occupational distributions by race and ethnicity in the U.S. considered periods before 2011. To my knowledge, no study has looked at the extent of occupational differences by race and ethnicity in the U.S. labor market from 2007 to 2018. Hence, this study updates and extends previous studies by examining the trend and patterns of differences in occupational distributions by race and ethnicity in the U.S. labor market from 2007 to 2018. Second, to my knowledge, there has been no study that has examined factors for disparities in occupational distributions by race and ethnicity in the U.S labor market from 2007 to 2018. This study, therefore, conducts micro-level analyses to examine whether racial and ethnic disparities in occupational distributions in the U.S. labor market were due to differences in workers' socio-demographic characteristics or due to other unexplained factors over this twelve-year period.

The paper is organized as follows: Section 2 discusses empirical analysis, Section 3 describes data, Section 4 presents results, and Section 5 presents conclusions.

\section{Empirical Analysis}

The empirical analysis that I apply in this study is similar to that of Gabriel et al. (1990). First, I consider the occupational attainment model to examine whether socio-demographic variables influence an individual's occupational attainment. Second, I apply the Oaxaca (1973) decomposition technique to examine whether disparities in occupational distributions by race and ethnicity are due to differences in socio-demographic characteristics of workers or due to other unexplained factors. In my empirical analysis, workers are classified as minority and nonminority workers. Minority workers are two kinds: African Americans(Note 2) and Hispanics(Note 3). Non-minority workers represent Whites(Note 4).

Considering the occupational attainment model, I assume that individuals are employed in an occupation as a result of their socio-demographic characteristics such as education, personal and family background characteristics, and employment opportunities in the region of their residence. These socio-demographic variables are listed in detail in Table 2 and are considered explanatory variables based on the human capital and occupational attainment literature such as Becker (1975), Mincer (1974), Schmidt and Strauss (1975), and Gabriel et al. (1990). Thus, the probability, $p_{i j}$, that the individual $i$ is employed in occupation $j$ is estimated by the following multinomial logit model:

$$
p_{i j}=\frac{\exp \left(X_{i} \beta_{j}\right)}{1+\sum_{k=1}^{J} \exp \left(X_{i} \beta_{k}\right)} \quad \text { for } i=1,2, \ldots, \mathrm{n} ; \quad j=1,2, \ldots, J
$$

Where $X_{i}$ represents a vector of individual's socio-demographic variables listed in Table 2; and $\beta_{\mathrm{j}}$ is a vector of coefficients corresponding to the $j$ th occupation. Equation (1) is estimated for a full sample of employed workers for each period from 2007 to 2018. 
Table 2. Definition of Explanatory Variables

\begin{tabular}{ll}
\hline Variable & \multicolumn{1}{c}{ Definition } \\
\hline African American & Set equal to 1 if an individual is African American and non-Hispanic, \\
& 0 otherwise \\
Hispanic & Set equal to 1 if an individual is Hispanic, 0 otherwise \\
Female & Set equal to 1 if an individual is female, 0 otherwise \\
Age & Age of an individual in years \\
Age squared & Age $\times$ Age \\
Some college & Set equal to 1 if an individual has received some college, 0 otherwise \\
Bachelor's degree or & Set equal to 1 if an individual has received Bachelor's degree or more \\
more & education, 0 otherwise \\
Married & Set equal to 1 if an individual is married, 0 otherwise \\
Child & Set equal to 1 if an individual has at least one child, 0 otherwise \\
Child under 5 years & Set equal to 1 if an individual has at least one child under 5 years of \\
& age, 0 otherwise \\
Northeast & Set equal to one if an individual lives in a Northeast state, 0 otherwise \\
Midwest & Set equal to one if an individual lives in a Midwest state, 0 otherwise \\
West & Set equal to one if an individual lives in a Western state, 0 otherwise \\
\hline
\end{tabular}

Following this, I apply the Oaxaca (1973) decomposition method to examine whether the differences in occupational distributions between White workers and minority workers are due to observed socio-demographic variables or due to unexplained variables. The unexplained explanatory variables could be discrimination or/and unobserved variables such as workers' labor market choices. The Oaxaca decomposition method has four important steps. In the first step, I examine factors that determine the occupational attainment of White workers of the labor market. Hence, I estimate (1) separately only for White workers and obtain the estimated parameter coefficients (that is, $\hat{\beta}_{j}$ ) of the explanatory variables of White workers. In the second step, I apply the estimated parameter coefficients (that is, $\hat{\beta}_{j}$ ) of White workers to individuals' characteristics from the minority samples, such as African American and Hispanic samples. This step generates the occupational distribution that minority workers would have if their characteristics were evaluated according to the estimated occupational structure for White workers. Hence, the predicted probability, $p_{i}^{m j}$, that the minority worker $i$ is employed in the occupation $j$ is given by

$$
p_{i}^{m j}=\frac{\exp \left(X_{m i} \widehat{\beta}_{j}\right)}{1+\sum_{k=1}^{J} \exp \left(X_{m i} \widehat{\beta}_{k}\right)} \quad \text { for } j=1,2, \ldots, J
$$

where $X_{m i}$ is a vector of socio-demographic characteristics of minority workers, and $\hat{\beta}_{j}$ is the estimated coefficients from the White occupational model. 
The third step is to get a predicted occupational distribution for each minority group. This is accomplished by summing (2) across all the workers of each minority group (that is, African American and Hispanic samples, respectively) for each occupation. This step yields

$$
E_{m j}=\sum_{m i} P_{i}^{m j}
$$

where $E_{m j}$ refers to as the "predicted", "expected", or "discrimination-free" number of workers of a minority group in the occupation $j$.

The fourth and the final step is to compare the actual occupational distribution of Whites with the actual and predicted occupational distribution of each minority group. There are two ways to make these comparisons. The first way to compare the actual occupational distribution of Whites with the actual and predicted occupational distribution of each minority group is by calculating the actual and predicted segregation index of Whites and the minority group. Following earlier studies such as Gabriel et al. (1990), Gabriel and Schmitz (2007), Queneau (2009), and Brown et al. (2014), I use the Index of Dissimilarity (ID), a methodology developed by Duncan and Duncan (1955), to measure the occupational segregation index of Whites and the minority group. The Index of Dissimilarity is defined as

$$
I D=\frac{1}{2} \sum_{j=1}^{J}\left|W_{j}-M_{j}\right|
$$

where $W_{j}$ is the percentage of the White workers in the occupation $j$, and $M_{j}$ is the percentage of the relevant minority workers in the occupation $j$. The value of $I D$ ranges from 0 to 100 , and its numerical value indicates the percentage of White workers or relevant minority workers that would need to change occupations for the two groups to reach equal occupational distribution. If $I D$ equals a zero value, then White and minority workers are evenly distributed across occupations. However, if $I D$ equals a hundred, then all occupations are completely segregated by race or ethnicity. Therefore, to measure the unexplained occupational differences between White workers and minority workers, first I use the equation (4) to measure the actual segregation index of White workers and minority workers, and then I use the following equation (5) below to measure the predicted occupational segregation index of Whites and the relevant minority group $\left(I D^{\prime}\right)$ :

$$
I D^{\prime}=\frac{1}{2} \sum_{j=1}^{J}\left|W_{j}-E_{j}\right|
$$

where $E_{j}$ is the predicted minority occupational distribution derived from the equation (3). If the predicted occupational segregation index of White and minority group (ID') is less than the actual occupational segregation index of Whites and minority group (ID), then I regard this supporting the proposition that unexplained explanatory variables are sources of occupational disparities between Whites and the relevant minority group.

The second way to compare the actual occupational distribution of Whites with the actual and predicted occupational distribution of each minority group is by performing the detail comparisons of percentage change in the actual and predicted occupational distribution by race 
and ethnicity in each occupational category. This second method gives a deeper understanding on why a relevant minority group is either underrepresented or overrepresented in a certain occupational category. There are three steps involved in this second method. In the first step, for each occupational group, I find the difference between actual occupational distribution of Whites and actual occupational distributions of a minority group, and I name this difference as the 'actual difference' in occupational distributions between Whites and the relevant minority group. In the second step, for each occupational category, I find the difference between the actual occupational distribution of Whites and the predicted occupational distribution of a minority group, and I consider this difference as the 'explained difference' in occupational distributions between Whites and the relevant minority group. 'Explained difference' represents the difference in observed socio-demographic characteristics between Whites and the relevant minority group. In the last step, for each occupational category, I find the difference between 'actual difference' and 'explained difference', and I refer to this difference as the 'unexplained difference' in occupational distributions between Whites and the relevant minority group. Often, this 'unexplained difference' in occupational distributions between Whites and a minority group in an occupational category is attributed to discrimination or/and other unobserved explanatory variables such as labor market choices of workers.

\section{Data}

Data for this study come from the Integrated Public Use Microdata Series (IPUMS) USA data set. The IPUMS USA data set consists of individual-level data on socio-demographic and occupational characteristics of workers in the U.S. The most recent available data in the IPUMS USA data set is for the year 2018(Note 5). Hence, I analyze the extent and the factors for differences in occupational distributions by race and ethnicity in the U.S. labor market from 2007 to 2018.

Regarding the sample selection, I consider all individuals aged 20 years and above. Race refers to two mutually exclusive groups: White non-Hispanics and African American non-Hispanics. Ethnicity refers to two mutually exclusive groups: White non-Hispanics and Hispanics. There are twenty-three occupational groups based on the Standard Occupational Classification (SOC) system of the Bureau of Labor Statistics of the United States. However, for tractability, I aggregate two to more similar occupational groups of the SOC to create these six major occupational groups(Note 6): Management, professional, and related; Military; Natural resources, construction, and maintenance; Production and transportation; Sales and office; and Service. Table 3 provides detailed information on how I grouped twenty-three SOC occupational categories to form six major occupational groups. Finally, based on the IPUMS recommendation, I use the person weight (PERWT) variable to create statistics that are nationally representative of individuals. 
Table 3. Occupational Categories

\begin{tabular}{ll}
\hline Occupational groups & Occupations included \\
\hline Management, professional, & Management \\
and related occupations & Business and Financial Operations \\
& Computer and Mathematical Operations \\
& Architecture and Engineering \\
& Life, Physical and Social Science \\
& Healthcare Practitioners and Technical \\
& Community and Social Service \\
& Legal \\
& Education, Training and Library \\
& Arts, Design, Entertainment, Sports, and Media \\
& Healthcare Support \\
Service occupations & Protective Service \\
& Food Preparation and Serving Related \\
& Building and Grounds Cleaning and Maintenance \\
Personal Care and Service \\
Production, transportation, & Sales and Related \\
and material moving occupations & Office and Administrative Support \\
Military & Pransportation and Material Moving \\
Natural resources, construction, & Farming, Fishing and Forestry \\
and maintenance occupations & Construction and Extraction \\
& Installation, Maintenance, and Repair \\
& \\
& \\
& \\
&
\end{tabular}

\section{Results}

First, I estimated the occupational attainment model specified in equation (1) for all employed individuals from the IPUMS data for each year from 2007 to 2018. The model includes controls for socio-demographic variables such as race, ethnicity, gender, age, education, marital status, children, and the region of residence. The base occupational category is management, professional, and related occupations. I find that the signs and coefficients of sociodemographic variables for equation (1) are similar across all years from 2007 to 2018. Hence, I have only presented results of the recent year, that is, 2018, in Table 4(Note 7). 
Table 4. Multinomial Logit Results for Occupational Attainment for all Workers, 2018

\begin{tabular}{|c|c|c|c|c|c|}
\hline Variable & $\ln (\mathrm{P} 1 / \mathrm{P} 6)$ & $\ln (\mathrm{P} 2 / \mathrm{P} 6)$ & $\ln (\mathrm{P} 3 / \mathrm{P} 6)$ & $\ln (\mathrm{P} 4 / \mathrm{P} 6)$ & $\ln (\mathrm{P} 5 / \mathrm{P} 6)$ \\
\hline \multirow[t]{2}{*}{ African American } & 0.6118 & 0.1254 & -0.3210 & 0.6333 & 0.2799 \\
\hline & $(0.0008)$ & $(0.0008)$ & $(0.0013)$ & $(0.0009)$ & $(0.0047)$ \\
\hline \multirow[t]{2}{*}{ Hispanic } & 0.6201 & 0.1925 & 0.6707 & 0.5309 & -0.1301 \\
\hline & $(0.0009)$ & $(0.0008)$ & $(0.0010)$ & $(0.0010)$ & $(0.0048)$ \\
\hline \multirow[t]{2}{*}{ Female } & 0.0276 & 0.3212 & -3.1710 & -1.4590 & -2.2261 \\
\hline & $(0.0006)$ & $(0.0005)$ & $(0.0014)$ & $(0.0007)$ & $(0.0050)$ \\
\hline \multirow[t]{2}{*}{ Age } & -0.0799 & -0.0597 & 0.0110 & -0.0225 & -0.1988 \\
\hline & $(0.0001)$ & $(0.0001)$ & $(0.0002)$ & $(0.0002)$ & $(0.0012)$ \\
\hline \multirow[t]{2}{*}{ Age squared } & 0.0007 & 0.0006 & -0.0002 & 0.0002 & 0.0009 \\
\hline & $(0.0000)$ & $(0.0000)$ & $(0.0000)$ & $(0.0000)$ & $(0.0000)$ \\
\hline \multirow[t]{2}{*}{ Some college } & -0.9545 & -0.5869 & -1.2740 & -1.3389 & -0.5069 \\
\hline & $(0.0007)$ & $(0.0007)$ & $(0.0009)$ & $(0.0008)$ & $(0.0039)$ \\
\hline \multirow[t]{2}{*}{ Bachelor's degree or more } & -2.7577 & -1.8207 & -3.7005 & -3.3752 & -1.5140 \\
\hline & $(0.0008)$ & $(0.0006)$ & $(0.0012)$ & $(0.0010)$ & $(0.0041)$ \\
\hline \multirow[t]{2}{*}{ Married } & -0.4554 & -0.1963 & -0.1765 & -0.3451 & 0.9607 \\
\hline & $(0.0007)$ & $(0.0006)$ & $(0.0009)$ & $(0.0007)$ & $(0.0041)$ \\
\hline \multirow[t]{2}{*}{ Child } & 0.0465 & -0.0526 & 0.0877 & 0.0070 & 0.1116 \\
\hline & $(0.0007)$ & $(0.0006)$ & $(0.0010)$ & $(0.0008)$ & $(0.0054)$ \\
\hline \multirow[t]{2}{*}{ Child under 5 years } & -0.0977 & -0.0906 & 0.0611 & -0.0655 & -0.2108 \\
\hline & $(0.0011)$ & $(0.0009)$ & $(0.0013)$ & $(0.0012)$ & $(0.0056)$ \\
\hline \multirow[t]{2}{*}{ Northeast } & 0.1309 & -0.0165 & -0.1334 & -0.0787 & -1.3326 \\
\hline & $(0.0008)$ & $(0.0007)$ & $(0.0011)$ & $(0.0010)$ & $(0.0068)$ \\
\hline \multirow[t]{2}{*}{ Midwest } & 0.1026 & 0.0095 & -0.0108 & 0.3570 & -1.3889 \\
\hline & $(0.0008)$ & $(0.0007)$ & $(0.0010)$ & $(0.0008)$ & $(0.0061)$ \\
\hline \multirow[t]{2}{*}{ West } & 0.0172 & -0.0361 & -0.1479 & -0.1535 & 0.0397 \\
\hline & $(0.0008)$ & $(0.0007)$ & $(0.0010)$ & $(0.0009)$ & $(0.0037)$ \\
\hline \multirow[t]{2}{*}{ Constant } & 2.2992 & 1.6085 & 0.7754 & 1.4666 & 2.3029 \\
\hline & $(0.0028)$ & $(0.0026)$ & $(0.0039)$ & $(0.0032)$ & $(0.0198)$ \\
\hline Pseudo R-squared & 0.1654 & & & & \\
\hline Log Likelihood & $6.29 \mathrm{E}+07$ & & & & \\
\hline Number of observations & 127553752 & & & & \\
\hline
\end{tabular}

Notes: Standard errors are in parentheses. The occupational classifications are the following: P1 = Service, P2 = Sales and office, P3 = Natural resources, construction, and maintenance, P4 $=$ Production, transportation, and material moving, P5 = Military, P6 = Management, professional and related.

Table 4 shows that African Americans and Hispanics are more likely than Whites to be employed in service, sales and office, and production, transportation, and material moving occupations as opposed to managerial, professional, and related occupations. African 
Americans, relative to Whites, are less likely to be employed in natural resources, construction, and maintenance jobs and more likely to be employed in military occupations. Hispanics are more likely to be working in natural resources, construction, and maintenance occupations and less likely to be employed in military occupations. Women are more likely to be employed in service and sales and office occupations and are less likely to be working in production, transportation, and material moving, natural resources, construction, and maintenance, and military occupations. Each additional age decreases the likelihood of working in service, sales and office, production, transportation, and material moving, and military occupations. Married individuals and individuals with children are less likely to be employed in sales and office occupations as opposed to managerial, professional, and related occupations. Individuals living in the Northeast, Midwest, and West than those in the South are more likely to be employed in service occupations. Of all the explanatory variables, the coefficients of education variables, particularly Bachelor's degree or more, have the largest negative effects on the likelihood of an individual being employed in service, sales and office, production, transportation, and material moving, natural resources, construction, and maintenance, and military occupations. Not surprisingly, this means, individuals with some college or Bachelor's degree or more education are more likely to be employed in managerial, professional, and related occupations than other five occupational categories. In summary, Table 4 shows that the coefficients of all socio-demographic variables are statistically significant and have expected signs, thereby suggesting that socio-demographic variables included in equation (1) are good predictors of occupational attainment.

Table 5 presents actual occupational distributions of Whites, African Americans, and Hispanics along with the predicted occupational distributions of African Americans and Hispanics. The predicted occupational distributions of African Americans and Hispanics are obtained from assigning African Americans and Hispanics to occupations according to the White multinomial logit model. The actual occupational distributions of Whites and African Americans from the first two columns of Table 5 show that these two racial groups had consistently experienced different occupations from 2007 to 2018 . Whether the U.S. economy was going through the Great Recession (from 2007 to 2009) or an economic recovery (from 2010 to 2018), African Americans, relative to Whites, were underrepresented in managerial, professional, and related occupations, and natural resource, construction, and maintenance occupations and overrepresented in service, and production, transportation, and moving jobs. During these twelve years, African Americans and Whites were almost equally distributed in military and sales and office occupations.

Regarding Hispanics, Table 5 shows that over the twelve-year period, they were underrepresented just like African Americans in management, professional, and related occupations and overrepresented in production, transportation, and moving, and service occupations. Unlike Whites and African Americans, they were more likely to be working in natural resource, construction, and maintenance jobs and less likely to be employed in sales and office and military occupations. These findings are similar to the ones found in earlier studies that measured racial and ethnic disparities in occupational distribution in years before 2011 (e.g. Alonso-Villar et al. 2012, Hamilton et al. 2011). 


\section{Macrothink}

Research in Applied Economics

ISSN 1948-5433

2021, Vol. 13, No. 2

Table 5. Actual and (multinomial logit) Predicted Occupational Distributions of White NonHispanics, African American Non-Hispanics, and Hispanics, 2007-2018 (all Figures are Expressed as Percentages)

\begin{tabular}{|c|c|c|c|c|c|}
\hline \multirow[b]{3}{*}{ Occupations } & \multicolumn{3}{|l|}{ Actual } & \multicolumn{2}{|l|}{ Predicted } \\
\hline & \multirow[b]{2}{*}{ Whites } & \multicolumn{2}{|l|}{ African } & \multicolumn{2}{|l|}{ African } \\
\hline & & Americans & Hispanics & Americans & Hispanics \\
\hline \multicolumn{6}{|l|}{2007} \\
\hline Management, professional, and related & 39.68 & 27.82 & 18.14 & 32.24 & 25.80 \\
\hline Military & 0.36 & 0.49 & 0.27 & 0.40 & 0.68 \\
\hline Natural resources, construction, and maintenance & 9.84 & 6.44 & 18.83 & 10.63 & 15.86 \\
\hline Production, transportation, and material moving & 11.33 & 16.29 & 18.25 & 12.37 & 15.00 \\
\hline Sales and office & 25.98 & 25.64 & 20.68 & 28.58 & 26.49 \\
\hline Service & 12.82 & 23.32 & 23.83 & 15.78 & 16.16 \\
\hline \multicolumn{6}{|l|}{2008} \\
\hline Management, professional, and related & 39.98 & 28.49 & 18.85 & 33.05 & 26.65 \\
\hline Military & 0.38 & 0.52 & 0.32 & 0.42 & 0.72 \\
\hline Natural resources, construction, and maintenance & 9.58 & 6.11 & 17.62 & 10.15 & 15.17 \\
\hline Production, transportation, and material moving & 11.12 & 15.67 & 17.92 & 11.82 & 14.49 \\
\hline Sales and office & 25.79 & 25.40 & 21.30 & 28.44 & 26.35 \\
\hline Service & 13.15 & 23.80 & 23.99 & 16.11 & 16.62 \\
\hline \multicolumn{6}{|l|}{2009} \\
\hline Management, professional, and related & 40.65 & 28.74 & 19.14 & 33.55 & 25.72 \\
\hline Military & 0.41 & 0.57 & 0.31 & 0.46 & 0.73 \\
\hline Natural resources, construction, and maintenance & 9.12 & 5.74 & 16.49 & 9.68 & 14.06 \\
\hline Production, transportation, and material moving & 10.56 & 14.93 & 17.01 & 11.24 & 13.50 \\
\hline Sales and office & 25.57 & 25.42 & 21.25 & 28.23 & 25.54 \\
\hline Service & 13.68 & 24.59 & 25.80 & 16.83 & 17.11 \\
\hline \multicolumn{6}{|l|}{2010} \\
\hline Management, professional, and related & 40.96 & 29.17 & 19.58 & 33.91 & 26.86 \\
\hline Military & 0.39 & 0.50 & 0.32 & 0.43 & 0.72 \\
\hline Natural resources, construction, and maintenance & 8.88 & 5.42 & 15.68 & 9.31 & 13.83 \\
\hline Production, transportation, and material moving & 10.61 & 14.99 & 16.78 & 11.26 & 13.81 \\
\hline Sales and office & 25.26 & 25.19 & 21.55 & 27.94 & 26.46 \\
\hline Service & 13.90 & 24.72 & 26.09 & 17.14 & 18.32 \\
\hline \multicolumn{6}{|l|}{2011} \\
\hline Management, professional, and related & 41.14 & 29.02 & 19.69 & 34.21 & 26.89 \\
\hline Military & 0.38 & 0.42 & 0.27 & 0.42 & 0.70 \\
\hline Natural resources, construction, and maintenance & 8.80 & 5.36 & 15.43 & 9.21 & 13.52 \\
\hline Production, transportation, and material moving & 10.74 & 15.18 & 16.93 & 11.38 & 14.13 \\
\hline Sales and office & 24.85 & 24.70 & 21.52 & 27.45 & 26.07 \\
\hline Service & 14.09 & 25.32 & 26.17 & 17.33 & 18.68 \\
\hline
\end{tabular}




\section{Macrothink}

Research in Applied Economics

ISSN 1948-5433

2021, Vol. 13, No. 2

2012

Management, professional, and related

41.10

28.79

20.08

34.00

27.24

Military

0.37

0.43

0.31

0.40

0.69

Natural resources, construction, and maintenance

8.78

5.30

15.39

9.31

13.40

Production, transportation, and material moving

10.82

15.20

17.00

11.55

14.12

Sales and office

24.76

25.23

21.25

27.19

25.82

Service

14.17

25.05

25.97

17.54

18.74

2013

Management, professional, and related

41.61

28.91

20.18

34.16

27.58

Military

0.35

0.42

0.31

0.37

0.64

Natural resources, construction, and maintenance

8.58

5.19

15.70

9.11

13.22

Production, transportation, and material moving

10.86

15.33

16.60

11.60

14.21

Sales and office

24.43

24.89

21.18

27.03

25.69

Service

14.18

25.26

26.02

17.73

18.67

2014

Management, professional, and related

42.41

29.58

20.89

34.94

28.56

Military

0.32

0.32

0.28

0.35

0.58

Natural resources, construction, and maintenance

8.56

5.20

15.59

9.06

13.02

Production, transportation, and material moving

10.94

15.60

16.63

11.71

14.26

Sales and office

23.80

24.54

21.22

26.30

25.02

Service

13.97

24.75

25.39

17.64

18.56

2015

Management, professional, and related

42.85

29.58

21.20

35.08

28.99

Military

0.34

0.38

0.29

0.36

0.60

Natural resources, construction, and maintenance

8.66

5.11

15.82

9.27

13.14

Production, transportation, and material moving

10.90

16.12

16.52

11.78

14.15

Sales and office

23.63

24.33

21.18

26.22

25.06

Service

13.63

24.47

24.98

17.29

18.06

2016

Management, professional, and related

43.41

29.84

21.75

35.50

29.53

Military

0.33

0.37

0.26

0.38

0.55

Natural resources, construction, and maintenance

8.47

5.06

15.80

9.16

12.80

Production, transportation, and material moving

10.72

16.25

16.32

11.62

14.06

Sales and office

23.38

24.18

20.99

25.92

24.81

Service

13.69

24.29

24.88

17.43

18.26

2017

Management, professional, and related

44.10

30.46

22.67

36.29

30.44

Military

0.33

0.33

0.29

0.36

0.56

Natural resources, construction, and maintenance

8.45

5.08

15.80

9.14

12.76

Production, transportation, and material moving

10.65

16.58

16.20

11.65

13.84

Sales and office

22.98

23.70

20.85

25.42

24.51 


\begin{tabular}{llllll} 
Service & 13.49 & 23.85 & 24.19 & 17.12 & 17.90 \\
\hline 2018 & & & & & \\
Management, professional, and related & 44.48 & 30.89 & 23.32 & 36.65 & 31.27 \\
Military & 0.31 & 0.32 & 0.29 & 0.34 & 0.52 \\
Natural resources, construction, and maintenance & 8.39 & 5.10 & 15.76 & 9.15 & 12.53 \\
Production, transportation, and material moving & 11.57 & 18.55 & 17.34 & 12.91 & 15.01 \\
Sales and office & 21.74 & 21.27 & 19.24 & 23.78 & 22.79 \\
Service & 13.50 & 23.87 & 24.05 & 17.17 & 17.87 \\
\hline
\end{tabular}

The fourth column of Table 5 shows the predicted occupational distributions of African Americans when they were assigned occupations according to the White occupational structure. Compared to the actual occupational distributions of African Americans, the predicted occupational distributions of African Americans had higher percentage of African Americans in occupations such as managerial, professional, and related, natural resource, construction and maintenance, sales and office, and lower percentage in occupations such as service and production, transportation, and moving occupations. These findings suggest that most of the predicted shifting in occupations between the actual and predicted African American's occupational distribution results in African Americans moving from service, production, transportation, and moving jobs to managerial, professional, and related occupations, sales and office occupations, and natural resource, construction, and maintenance occupations. Similarly, for Hispanics, the predicted occupational distributions presented in the fifth column of Table 5 shows that Hispanics would be more likely to work in managerial, professional, and related, sales and office, and military occupations, and less likely to work in natural resources, construction, and maintenance, production, transportation and moving, and service jobs. These findings applied for all years from 2007 to 2018. Moreover, these results indicate that occupational distributions of African Americans and Hispanics would improve if their observed socio-demographic characteristics are evaluated according to the White occupational structure.

Table 6 shows the Index of Dissimilarity by race and ethnicity from 2007 to 2018 . The first column shows the actual Index of Dissimilarity across Whites' actual and African Americans' actual occupational distributions. In 2007, the racial differences in occupational distributions, as measured by the actual Index of Dissimilarity, were 15.60. This means, around 16 percent of African Americans or Whites would have to change occupations in order for the two racial groups to reach equal occupational distributions. During the periods of Great Recession, the overall racial disparity in occupational distributions was slightly less than 15.60 percent. But, by 2018 , racial differences in occupational distributions increased to 17.35 percent. As the overall racial disparity in occupational distributions have slightly increased from 2007 to 2018 , this finding is different from earlier studies such as Queneau (2009) and Gradin et al. (2015) that reported stable differences in occupational distributions between Whites and African Americans for periods before 2011.

The second column of Table 6 also shows the predicted Index of Dissimilarity across Whites' 
actual and African Americans' expected occupational distributions. In 2007, the predicted Index of Dissimilarity was 7.44 percent, which was about 52 percent less than the actual Index of Dissimilarity. This indicates that the disparity between the White and African American occupational distributions would be reduced by around 52 percent if African Americans were assigned to employments based on the estimated occupational model for Whites. In 2018, the predicted Index of Dissimilarity fell by about 55 percent when compared to the actual Index of Dissimilarity. These results suggest that the extent of the unexplained differences in the occupational distributions of Whites and African Americans increased slightly from 2017 to 2018. The unexplained differences in the occupational distributions of Whites and African Americans could represent discrimination, unobserved explanatory variables such as a worker's labor market choice, or some combination of the two.

Table 6. Index of Dissimilarity by Race and Ethnicity, 2007-2018 (all Figures are Expressed as Percentages)

\begin{tabular}{lllllll}
\hline \multicolumn{3}{c}{ African Americans } \\
Year & $\begin{array}{l}\text { Actual Index of Predicted Index Percentage } \\
\text { of Dissimilarity }\end{array}$ & \multicolumn{3}{c}{ Actual Index of Predicted Index PercentageDi } \\
& \multicolumn{2}{c}{ of Dissimilarity } & of Dissimilarity fference \\
\hline 2007 & 15.60 & 7.44 & -52.31 & 26.92 & 13.88 & -48.45 \\
2008 & 15.35 & 6.93 & -54.87 & 25.68 & 13.33 & -48.09 \\
2009 & 15.45 & 7.11 & -53.99 & 25.94 & 13.30 & -48.73 \\
2010 & 15.32 & 7.05 & -53.97 & 25.18 & 13.79 & -45.23 \\
2011 & 15.71 & 6.93 & -55.87 & 24.89 & 14.25 & -42.77 \\
2012 & 15.80 & 7.10 & -55.03 & 24.59 & 13.87 & -43.62 \\
2013 & 16.09 & 7.45 & -53.68 & 24.71 & 14.03 & -43.21 \\
2014 & 16.18 & 7.47 & -53.86 & 24.15 & 13.85 & -42.65 \\
2015 & 16.82 & 7.77 & -53.81 & 24.13 & 13.85 & -42.60 \\
2016 & 16.98 & 7.91 & -53.43 & 24.12 & 13.88 & -42.44 \\
2017 & 17.00 & 7.81 & -54.09 & 23.59 & 13.66 & -42.10 \\
2018 & 17.35 & 7.83 & -54.90 & 23.68 & 13.21 & -44.22 \\
\hline
\end{tabular}

For Hispanics, in 2007, the actual Index of Dissimilarity was around 27 percent, thereby suggesting that about 27 percent of Hispanics or White non-Hispanics would have to change jobs to get the two occupational distributions equal. During the Great Recession years, the actual Index of Dissimilarity across White non-Hispanics' actual and Hispanics' actual occupational distributions decreased by around 2 percentage points, and by 2018 , the actual Index of Dissimilarity fell by around 3 percentage points, to 23.68 percent. Hence, this study reveals that disparities in the occupational structures between actual White non-Hispanics and actual Hispanics had decreased from 2007 to 2018. Furthermore, over the twelve-year period, the difference in occupational distributions between actual White non-Hispanics and Hispanics 
was consistently greater than the disparity in occupational distributions between actual Whites and African Americans. This finding is similar to results of racial and ethnic disparities in occupational distribution reported in other studies such as Gabriel et al. (1990) and Queneau (2009).

Table 7 provides a detailed look at the percentage change in the actual and predicted occupational distribution by race and ethnicity in each occupational category in 2007 and 2018(Note 8). This table helps to gain a better understanding of the reasons why minority groups are overrepresented or underrepresented in an occupational category. In this Table 7, the first column, called 'actual difference', shows the percentage point difference between actual White percentage and actual African American percentage in an occupational category. The second column, called 'explained difference', shows the percentage point difference between actual White percentage and predicted African American percentage in an occupational category. This 'explained difference' accounts for the dissimilarity due to difference in observed explanatory (or socio-demographic) variables between Whites and African Americans. The last column, called 'unexplained difference', is the percentage point difference between the 'actual difference' and the 'explained difference' of each occupational category. The 'unexplained difference' accounts for the dissimilarity due to difference in unexplained variables such as discrimination or/and unobserved explanatory variables such as workers' labor market choices.

Table 7 shows that over 2007 to 2018, in management, professional, and related occupations, the actual difference between Whites and African Americans increased from 11.86 percentage points to 13.59 percentage points, the explained difference increased from 7.44 percentage points to 7.83 percentage points, and the unexplained difference increased from 4.42 percentage points to 5.76 percentage points. These findings reveal that there had been an increase in the underrepresentation of African Americans in management, professional, and related occupations over the twelve-year period, and the reason was largely due to unexplained variables. However, the results also indicate that socio-demographic factors had played a larger role than unexplained factors in the underrepresentation of African Americans in management, professional, and related occupations over the period. Between 2007 and 2018, African Americans were underrepresented in natural resources, construction, and maintenance occupations, and this was largely due to unexplained variables rather than observed sociodemographic variables of workers. Specifically, the unexplained difference accounted for about 4 percentage points to the actual difference between Whites and African Americans in natural resources, construction, and maintenance occupations. In production, transportation, and material moving occupations, African Americans were overrepresented than Whites mainly due to unexplained factors. Moreover, the unexplained difference in production, transportation, and moving occupations between Whites and African Americans increased from 3.92 percentage points in 2007 to 5.64 percentage points in 2018. Service occupations were other employment where African Americans were consistently overrepresented than Whites during 2007 to 2018. The unexplained difference accounted for a larger role in explaining racial dissimilarity in service occupations.

Turning to Hispanics, the actual difference between Whites and Hispanics remained relatively 
stable around 21 percentage points in management, professional and related occupations between 2007 and 2018. The amount of actual difference in management, professional and related occupations between Whites and Hispanics was higher than that of the actual difference between African Americans and Whites. However, as with African Americans, the explained difference (that is, observed socio-demographic variables) accounted for a larger contribution than the unexplained difference to the actual difference between Whites and Hispanics in this occupational category. In occupational categories such as sales and office occupations and service occupations, the unexplained difference accounted for a larger contribution than the explained difference in the actual difference between Whites and Hispanics, while in natural resources, construction and maintenance occupations, the explained difference accounted for a higher contribution to the actual difference between Whites and Hispanics. In production, transportation, and material moving occupations and military occupations, both explained difference and unexplained difference accounted nearly the same contribution to the actual difference between Whites and Hispanics.

Table 7. Change in the Occupational Distributions by Race and Ethnicity, 2007 and 2018 (all Figures are Expressed as Percentage Points)

\begin{tabular}{|c|c|c|c|c|c|c|}
\hline \multirow[b]{2}{*}{ Year } & \multicolumn{3}{|c|}{ Whites versus African Americans } & \multicolumn{3}{|c|}{ Whites versus Hispanics } \\
\hline & $\begin{array}{l}\text { Actual } \\
\text { Difference }\end{array}$ & $\begin{array}{l}\text { Explained } \\
\text { Difference }\end{array}$ & $\begin{array}{l}\text { Unexplaine } \\
\text { d } \\
\text { Difference }\end{array}$ & $\begin{array}{l}\text { Actual } \\
\text { Difference }\end{array}$ & $\begin{array}{l}\text { Explained } \\
\text { Difference }\end{array}$ & $\begin{array}{l}\text { Unexplained } \\
\text { Difference }\end{array}$ \\
\hline \multicolumn{7}{|c|}{ Management, professional, and related } \\
\hline 2007 & 11.86 & 7.44 & 4.42 & 21.53 & 13.88 & 7.66 \\
\hline 2018 & 13.59 & 7.83 & 5.76 & 21.16 & 13.21 & 7.95 \\
\hline \multicolumn{7}{|c|}{ Military } \\
\hline 2007 & -0.13 & -0.04 & -0.09 & 0.08 & -0.32 & 0.41 \\
\hline 2018 & -0.01 & -0.02 & 0.02 & 0.02 & -0.21 & 0.23 \\
\hline \multicolumn{7}{|c|}{ Natural resources, construction, and maintenance } \\
\hline 2007 & 3.40 & -0.79 & 4.19 & -8.99 & -6.02 & -2.97 \\
\hline 2018 & 3.29 & -0.76 & 4.05 & -7.37 & -4.14 & -3.23 \\
\hline \multicolumn{7}{|c|}{ Production, transportation, and material moving } \\
\hline 2007 & -4.97 & -1.05 & -3.92 & -6.92 & -3.67 & -3.25 \\
\hline 2018 & -6.98 & -1.34 & -5.64 & -5.77 & -3.44 & -2.32 \\
\hline \multicolumn{7}{|c|}{ Sales and office } \\
\hline 2007 & 0.33 & -2.60 & 2.94 & 5.30 & -0.52 & 5.82 \\
\hline 2018 & 0.47 & -2.03 & 2.51 & 2.50 & -1.05 & 3.55 \\
\hline \multicolumn{7}{|c|}{ Service } \\
\hline 2007 & -10.50 & -2.96 & -7.54 & -11.01 & -3.34 & -7.67 \\
\hline 2018 & -10.37 & -3.67 & -6.70 & -10.55 & -4.37 & -6.18 \\
\hline
\end{tabular}


Hence, Table 7 shows that unexplained variables in addition to socio-demographic variables played an important role in explaining why African Americans and Hispanics were underrepresented or overrepresented in an occupational category over the period. The unexplained variables that influenced racial and ethnic dissimilarity in each occupational category could be discrimination or/and labor market choices of minority workers.

\section{Conclusion}

Differences in occupational distributions by race and ethnicity are prominent issues for economists and policymakers because they can influence other forms of inequality such as racial and ethnic gaps in wage levels and wage growth in the society. Hence, this study examines the extent of differences in occupational distributions by race and ethnicity in the U.S. labor market for the most recent periods, which are from 2007 to 2018 . Additionally, the study examines the reasons why African Americans and Hispanics face different occupational structures relative to Whites in the U.S. labor market during this period.

This study found that compared to Whites, African Americans and Hispanics were underrepresented in the management, professional, and related occupational categories and were overrepresented in production, transportation, and material moving, and service employments from 2007 to 2018. This finding is similar to results from previous studies that examined differences in occupational distributions by race and ethnicity before 2007. This study also found that racial differences in occupational distributions were lower than the disparities in occupational distributions by ethnicity from 2007 to 2018. Racial disparity in occupational distributions increased slightly, but differences in occupational distributions by ethnicity decreased during the twelve-year period.

The study found that racial and ethnic disparities in occupational distributions in the U.S. labor market from 2007 to 2018 were not only due to observed socio-demographic variables of workers but also due to other unexplained factors. The effect of unexplained variables was found to have more pronounced effects on the racial differences in occupational distributions than on ethnic differences in occupational distributions over the period. The study also found that the impact of unexplained factors on racial and ethnic disparities in occupational distributions varied by the type of occupational categories. In managerial, professional, and related jobs, observed socio-demographic variables played larger roles than unexplained variables in creating differences in occupational distributions by race and ethnicity. In contrast, in occupational categories such as service employments, unexplained factors played larger roles than socio-demographic variables in explaining racial and ethnic disparities in occupational distributions.

The findings of this study recommend policy makers that we should consider both observed socio-demographic variables of workers and unexplained factors to eliminate differences in occupational distributions by the race and ethnicity in the U.S. labor market. If we believe unexplained factors represent discrimination and workers' labor market choices, then we need to work on policies that address these factors. For example, we might need to work on 
developing better policies that eliminate discrimination by race and ethnicity in workplace in all types of occupations. Similarly, we ought to provide good career networks and career guidance programs to African Americans and Hispanics at schools, colleges, and workplaces across all states of the United States. A good career network and guidance program can empower African Americans and Hispanics to make better labor market choices such as encouraging them to select managerial, professional, and related occupations over jobs such as production, transportation, and material moving, natural resources, construction and maintenance, and service employments.

Lastly, socio-demographic variables such as college education was found to play larger roles than unexplained variables in explaining racial and ethnic disparities in occupational distributions in managerial, professional, and related occupations. Hence, we ought to support programs and policies that help African Americans and Hispanics to earn college degrees. Having college degrees can help to narrow occupational differences by race and ethnicity in managerial, professional, and related occupations.

\section{Acknowledgement}

The author is thankful to the United Negro College Fund (UNCF) Career Pathways Initiative for awarding the 2018-2019 Faculty Research Grant to conduct this research.

\section{References}

Alonso-Villar, O., Del, R. C., \& Gradin, C. (2012). The extent of occupational segregation in the United States: Differences by race, ethnicity, and gender. Industrial Relations: A Journal of Economy and Society, 51(2), 179-212. https://doi.org/10.1111/j.1468232X.2012.00674.x

Alonso-Villar, O., Gradin, C., \& Del, R. C. (2013). Occupational segregation of Hispanics in US metropolitan areas. Applied Economics, 45(30), 4298-4307. https://doi.org/10.1080/00036846.2013.778951

Becker, G. S. (1975). Human Capital (2nd ed.). New York: National Bureau of Economic Research.

Blau, F., Brummund, P., \& Liu, A. (2013). Trends in occupational segregation by gender 19702009: Adjusting for the impact of changes in the occupational coding system. Demography, 50(2), 471-494. https://doi.org/10.1007/s13524-012-0151-7

Brown, R., Moon, M., \& Zoloth, B. (1980). Occupational attainment and segregation by sex. Industrial and Labor Relations Review, 33(4), 506-517. https://doi.org/10.1177/001979398003300405

Duncan, O., \& Duncan, B. (1955). A methodological analysis of segregation indexes. American Sociological Review, 20(2), 210-217. https://doi.org/10.2307/2088328 
Gabriel, P., Williams, D., \& Schmitz, S. (1990). The relative occupational attainment of young Blacks, Whites, and Hispanics. Southern Economic Journal, 57(1), 35-46. https://doi.org/10.2307/1060476

Gabriel, P., \& Schmitz, S. (2007). Gender differences in occupational distributions among workers. Monthly Labor Review, 130(6), 19-24.

Gradín, C., Del Río, C., \& Alonso-Villar, O. (2015). Occupational segregation by race and ethnicity in the United States: Differences across states. Regional Studies, 49(10), 1621 1638. https://doi.org/10.1080/00343404.2013.864384

Hamilton, D., Austin, A., \& Darity, W. (2011). Whiter Jobs, Higher Wages: Occupational segregation and the lower wages of black men. Economic Policy Institute Briefing Paper, 288. Retrieved 30 October, 2018, from https://files.epi.org/page/-/BriefingPaper288.pdf

Hellerstein, J., \& Neumark, D. (2008). Workplace segregation in the United States: Race, ethnicity, and skill. The Review of Economics and Statistics, 90(3), 459-477.

Mincer, J. (1974). Schooling, experience, and earnings. New York: National Bureau of Economic Research; distributed by Columbia University Press.

Oaxaca, R. (1973). Male-female wage differentials in urban labor markets. International Economic Review, 14(3), 693-709. https://doi.org/10.2307/2525981

Queneau, H. (2006). Changes in occupational segregation by gender and race-ethnicity in healthcare: Implications for policy and union practice. Labor Studies Journal, 31(1), 7190. https://doi.org/10.1177/0160449X0603100105

Queneau, H. (2009). Trends in occupational segregation by race and ethnicity in the USA: evidence from detailed data. Applied Economics Letters, 16(13), 1347-1350. https://doi.org/10.1080/13504850701367346

Ruggles, S., Flood, S., Goeken, R., Grover, J., Meyer, E., Pacas, J., \& Sobek, M. (2020). IPUMS USA: Version 10.0 [dataset]. Minneapolis, MN: IPUMS. https://doi.org/10.18128/D010.V10.0

Schmidt, P., \& Strauss, R. (1975). The prediction of occupation using multiple logit models. International Economic Review, 16(2), 471-486. https://doi.org/10.2307/2525826

Semyonov, M., Haberfeld, Y., Cohen, Y., \& Lewin-Epstein, N. (2000). Racial composition and occupational segregation and inequality across American cities. Social Science Research, 29(2), 175-187. https://doi.org/10.1006/ssre.1999.0662

Tomaskovic-Devey, D., Stainback, K., Taylor, T., Zimmer, C., Robinson, C., \& McTague, T. (2006). Documenting desegregation: Segregation in American workplaces by race, ethnicity, and sex, 1966-2003. American Sociological Review, 71(4), 565-588. https://doi.org/10.1177/000312240607100403

U.S. Bureau of Labor Statistics. Retrieved 30 October, 2018 from https://data.bls.gov/timeseries/LNS14000006 


\section{Notes}

Note 1. In 2018, according to the U.S. Census Bureau, African Americans were the largest racial minority, comprising of around $14.62 \%$ of the total U.S. population. Hispanics represented the largest ethnic minority, consisting of around $18.3 \%$ of the total U.S. population. Retrieved on May 17, 2021 from https://www.census.gov/data/datasets/timeseries/demo/popest/2010s-national-detail.html.

Note 2. African Americans refer to non-Hispanic African Americans.

Note 3. Hispanics refer to persons of Hispanic/Spanish/Latino origin.

Note 4. Whites refer to White non-Hispanic people.

Note 5. In June 2020, the IPUMS USA data set had the most recent available data for the year 2018 .

Note 6. The six occupational categories are similar to occupational categories reported in the Bureau of Labor Statistics' publication called "Labor force characteristics by race and ethnicity, 2018," which was published in https://www.bls.gov/opub/reports/race-andethnicity/2018/pdf/home.pdf and was accessed on June 23, 2020. Moreover, previous studies in occupational segregation literature have also considered a broad measure of major occupational groups (e.g., Gabriel et al. 1990, Semyonov et al. 2000, and Queneau 2009).

Note 7. Results from other years are available upon request.

Note 8 . Table 7 only presents results for 2007 and 2018. Results for other years are available upon request.

\section{Copyright Disclaimer}

Copyright for this article is retained by the author(s), with first publication rights granted to the journal.

This is an open-access article distributed under the terms and conditions of the Creative Commons Attribution license (http://creativecommons.org/licenses/by/3.0/). 